\title{
Article \\ One-Pot Synthesis of Copper Iodide-Polypyrrole Nanocomposites
}

\author{
Artem O. Konakov ${ }^{1,2}$, Nadejda N. Dremova ${ }^{1}$, Igor I. Khodos ${ }^{3}$, Marcus Koch ${ }^{4}$, Ekaterina V. Zolotukhina ${ }^{1,2,5, * \mathbb{D}}$ \\ and Yuliya E. Silina ${ }^{6, *(D)}$
}

check for updates

Citation: Konakov, A.O.; Dremova, N.N.; Khodos, I.I.; Koch, M.;

Zolotukhina, E.V.; Silina, Y.E. One-Pot Synthesis of Copper

Iodide-Polypyrrole Nanocomposites. Chemosensors 2021, 9, 56. https://

doi.org/10.3390/chemosensors9030056

Academic Editor: Vardan Galstyan

Received: 19 February 2021

Accepted: 10 March 2021

Published: 16 March 2021

Publisher's Note: MDPI stays neutral with regard to jurisdictional claims in published maps and institutional affiliations.

Copyright: (c) 2021 by the authors. Licensee MDPI, Basel, Switzerland. This article is an open access article distributed under the terms and conditions of the Creative Commons Attribution (CC BY) license (https:// creativecommons.org/licenses/by/ $4.0 /)$.
1 Institute of Problems of Chemical Physics of Russian Academy of Sciences, 142432 Chernogolovka, Russia; artjom7777@gmail.com (A.O.K.); nti@icp.ac.ru (N.N.D.)

2 Faculty of Fundamental Physical and Chemical Engineering, Lomonosov Moscow State University, 119991 Moscow, Russia

3 Science Center in Chernogolovka, Russian Academy of Sciences, 142432 Chernogolovka, Russia; info@npenergy.ru

4 INM-Leibniz Institute for New Materials, Campus D2 2, 66123 Saarbrücken, Germany; Marcus.Koch@leibniz-inm.de

5 Moscow Institute of Physics and Technology, National Research University, 141701 Dolgoprudny, Russia

6 Institute for Biochemistry, Centre of Human and Molecular Biology, Campus B 2.2, University of Saarland, 66123 Saarbrücken, Germany

* Correspondence: zolek@icp.ac.ru (E.V.Z.); yuliya.silina@uni-saarland.de or yuliya.silina@gmx.de (Y.E.S.)

Abstract: A novel one-pot chemical synthesis of functional copper iodide-polypyrrole composites, CuI-PPy, has been proposed. The fabrication process allows the formation of nanodimensional metal salt/polymer hybrid structures in a fully controlled time- and concentration-dependent manner. The impact of certain experimental conditions, viz., duration of synthesis, sequence of component addition and concentrations of the intact reagents on the structure, dimensionality and yield of the end-product was evaluated in detail. More specifically, the amount of marshite CuI within the hybrid composite can be ranged from 60 to $90 \mathrm{wt}$.\%, depending on synthetic conditions (type and concentration of components, process duration). In addition, the conditions allowing the synthesis of nano-sized CuI distributed inside the polypyrrole matrix were found. A high morphological stability and reproducibility of the synthesized nanodimensional metal-polymer hybrid materials were approved. Finally, the electrochemical activity of the formed composites was verified by cyclic voltammetry studies. The stability of CuI-PPy composite deposited on the electrodes was strongly affected by the applied anodic limit. The proposed one-pot synthesis of the hybrid nanodimensional copper iodide-polypyrrole composites is highly innovative, meets the requirements of Green Chemistry and is potentially useful for future biosensor development. In addition, this study is expected to generally contribute to the knowledge on the hybrid nano-based composites with tailored properties.

Keywords: one-pot synthesis; copper iodide; polypyrrole; hybrid composite; electrochemical activity

\section{Introduction}

Copper iodide (CuI) has a wide application in nonlinear optics [1,2], solar cells development [3], photocatalysis [4], photoluminescention [5], electrophysics [6,7] and conventional analytical chemistry, i.e., mercury detection [8]. Apart from those, $\mathrm{CuI}$ is used as a perspective catalyst in a large number of organic synthesis, viz., Heck-types reactions [9,10], Stills-types [11], Ullmann-type routes [12-19] Suzuki-Miyaura and Sonogashira reactions of cross-coupling [20-22] and many others [19,22-27]. In addition, CuI was reported as an effective electrocatalyst in hydrazine-related synthesis [28] and formic acid oxidation [29].

In general, the presence of catalytically active copper (I) leads to an increase in instability of the chemical content on the catalyst surface due to interaction with molecular oxygen and copper oxide formation [30]. To protect the surface of catalytically active copper (I) compound CuI, the synthesis of composites where copper iodide is included 
into the porous polymeric framework could be a promising strategy. In this case, the resulted metal-polymer structures can be electroactive and find numerous applications as permeable functional reagents.

Due to the ability toward enhanced electron transport, porosity and thermal stability, polypyppole and polyaniline can be considered as the most attractive types of conjugated polymers used for the protection of CuI. The synthesis of the hybrid composites utilizing polypyppole and representing the inorganic particles-conjugated polymers, which correspond to the abovementioned requirements, i.e., electroactivity and permeability, was introduced in our previous studies [31-33]. The proposed approach enables high reproducible morphology and advanced functional properties of the formed hybrids. The synthesis route is based on the direct chemical reaction occurring in a diluted aqueous solution between the inorganic precursor (salts) and targeted monomer. This chemical path leads to the formation of the hybrid composite in a powder form. The next step is the electrochemical co-deposition of the hybrid composite from this multicomponent electrolyte on the electrode by a double step polarization procedure. The electrochemical path results in a reliable film attachment on the electrode surface.

Remarkably, the synthesis of CuI was realized through the fast chemical redox reactions between copper (II) and iodide anions in the aqueous or ethanol-containing solutions $[34,35]$. As a result, multidimensional crystals of copper iodide with a size ranged from $300 \mathrm{~nm}$ to $5 \mu \mathrm{m}$ can be formed. In the presence of ethanol under the inert atmosphere, it is possible to decrease the crystals size of copper iodide to $50 \mathrm{~nm}$ [36]. Nevertheless, the stabilization of nanodimensional CuI crystals is possible only by use of polymers or surfactants. To the best of our knowledge, almost no attempts were made toward the formation of nanodimensional metal salt-polymer structures, i.e., CuI-polymer hybrids.

In general, copper iodide formation is a very rapid reaction, especially in comparison with the rates of monomer oxidative polymerization. As a consequence, the rapid formation of $\mathrm{CuI}$ particles leads to their subsequent aggregation in a solution without incorporation into the polymer matrix. In this regard, the synthesis process of $\mathrm{CuI}$ nanoparticles included into the polymer framework is difficult to control. For this goal, it is highly necessary to establish the experimental conditions of a facile one-pot redox-synthesis, where $\mathrm{CuI}$ nanoparticles can be reliably included into the conjugated polymer matrix.

The goal of this study was to develop a novel eco-friendly, one-pot synthesis methodology toward the formation of stable nanodimensional hybrid copper iodide-polypyrrole composites. The hybrid materials fabricated from an aqueous multicomponent solution were fully characterized via tandem of chemical analytical, electrochemical and physical assays, i.e., UV-Vis, laser desorption ionization mass spectrometry (LDI-MS), cyclic voltammetry $(\mathrm{CV})$, X-Ray diffraction analysis (XRD), scanning electron microscopy coupled $\mathrm{X}$-Ray spectral analysis (SEM/EDX) and transmission electron microscopy (TEM). More importantly, the obtained hybrid materials were approved as electroactive. This is an important criterion for the development of novel mediators used in chemical sensing and point-of-care diagnostic.

\section{Materials and Methods}

\subsection{Materials and Methods}

We used $99 \% \mathrm{CuSO}_{4}$ pentahydrate, (Ruskhim), 99\% potassium iodide (Vecton) and 0.1 M iodine solution (uPCR) as received. Pyrrole 99\% (Sigma Aldrich, Taufkirchen, Germany) was distilled under argon atmosphere prior to use. Nafion DE1020 $(10 \%)$ was obtained from DuPont (Sigma Aldrich, Taufkirchen, Germany). To prepare all working solutions, three-fold distilled water (SZ97A Automatic third pure-water distillatory, Shanghai Yarong Biochemistry instrument factory) was used.

The DRP-110DGPHOX screen-printed electrodes (SPE), were obtained from DropSens (Metrohm $\mathrm{GmbH}$, Filderstadt, Germany). Each sensor consisted of a carbon working electrode, modified with a layer of graphene oxide, (referred to as SPE/GO) or $\mathrm{TiO}_{2}-$ 
nanotubes $\left(\mathrm{SPE} / \mathrm{TiO}_{2}\right)$, a carbon counter electrode and a silver reference electrode. Organicfree, deionized water (DI) was generated by an Elga PureLab (Celle, Germany) system.

\subsection{One-Pot Composite Preparation and Deposition}

A total of $450 \mathrm{~mL}$ of a precursor pyrrole solution with various additives (Table 1) was mixed with $50 \mathrm{~mL}$ of copper sulphate. After mixing, the obtained solution was kept in an ultrasonic bath for several hours. The duration of synthesis, concentration of chemicals and addition sequence of the reacting components was varied in a wide range; see Table 1 . The efficiency of one-pot preparation approaches, depending on the experimental conditions, was estimated based on CuI product yield.

Table 1. The impact of experimental conditions on the product yield and copper iodide (CuI) content in the hybrid composite.

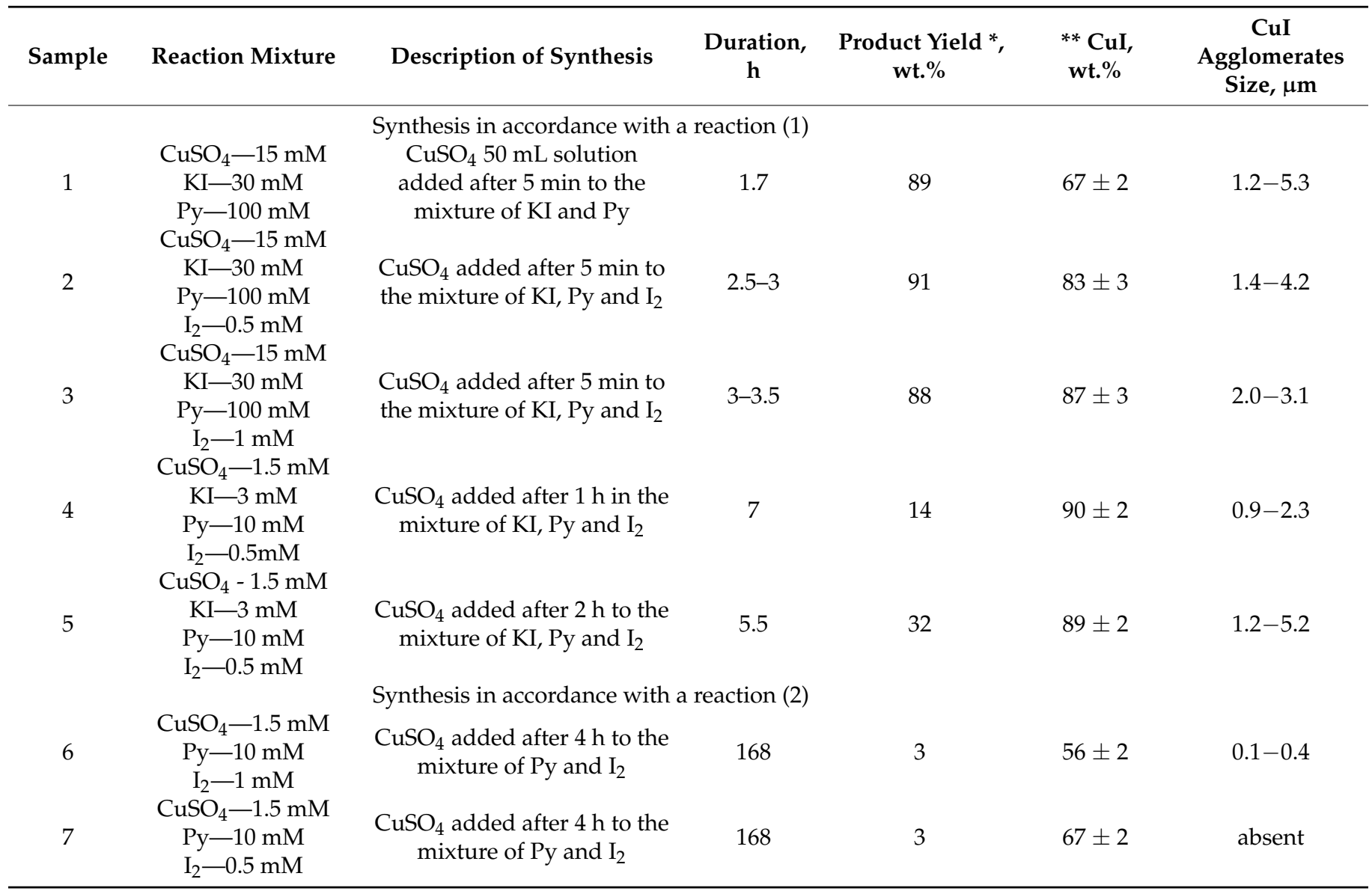

* Calculated based on the gravimetric analysis; ${ }^{* *}$ Calculated as average value of Thermogravimetry (TGA) and elemental CHNS+O (ash) analyses and confirmed by X-Ray spectral (EDX) studies.

Several hours after mixing, a gray-black powder was precipitated from the solution. The precipitate was separated from the synthetic mixture via centrifugation or by simple decantation of the supernatant. Afterwards, the precipitate was rinsed several times with DI water (50 $\mathrm{mL}$ per one rinsing procedure) and finally with ethanol-water solution $(1: 1 \mathrm{v} / \mathrm{v})$. During rinsing procedure, the mixture of composite and solvent was stirred on a Vortex or by simple shaking. Next, the solvent was removed under vacuum by Schlenk's line.

As a reference system, pure CuI was also used in our experiments. For this goal, $\mathrm{CuI}$ was obtained by direct redox reaction between copper sulphate and potassium iodide. The formed $\mathrm{CuI}$ in a powder form was separated from the solution and rinsed several times by DI water. 


\subsection{UV-Vis Spectroscopy}

To control the completeness of chemical reaction between the pyrrole solution with various additive reagents (Table 1), UV-Vis spectroscopy was utilized [32]. The reaction mixture was immersed to a quartz cuvette with a thickness of $10 \mathrm{~mm}$. The UV-Vis spectra were recorded in the range of 200-900 nm on a Lightwave II spectrophotometer (Biochrom, Cambridge, UK). All measurements were repeated at least in triplicates.

\subsection{Laser Desorption Ionization Mass Spectrometry (LDI-MS)}

To verify the efficiency of one-pot chemical synthesis performed from the multicomponent electrolyte solution (estimated as a presence of polypyrrole framework with entrapped $\mathrm{CuI})$, LDI-MS screening of SPE/GO and SPE/ $/ \mathrm{TiO}_{2}$ surfaces after dropping $(3 \mu \mathrm{L})$ of $\mathrm{CuI}-$ PPy powder was used. Prior to LDI-MS analysis, the modified electrodes were dried at $60{ }^{\circ} \mathrm{C}$ for $1 \mathrm{~h} \mathrm{[37].} \mathrm{The} \mathrm{analysis} \mathrm{was} \mathrm{carried} \mathrm{out} \mathrm{on} \mathrm{a} \mathrm{Bruker} \mathrm{Esquire} \mathrm{3000+ESI-ion} \mathrm{trap}$ MS (Bruker Daltonics, Bremen, Germany) operated by Bruker Esquire control 5.3 software equipped with atmospheric pressure AP-MALDI ion source and Nd:YAG solid-state laser $(200 \mathrm{~Hz}, 3 \mathrm{~ns})$. To provide a soft ionization of the tested layer and to prevent a strong thermal decomposition of polypyrrole, the source parameters were as follows: drying gas flow was set at $6 \mathrm{~L} / \mathrm{min}$; drying gas temperatures was $180^{\circ} \mathrm{C}$. Mass spectra were recorded in negative ionization mode.

\subsection{Scanning Electron Microscopy (SEM) with Coupled X-ray Analysis (EDX)}

The morphology of SPE/GO and $\mathrm{SPE} / \mathrm{TiO}_{2}$ before and after modification by CuIPPy was investigated by SEM/EDX. The electrodes were placed directly on the sample stage of a FEI (Hilsboro, OR, United States) Quanta 400 FEG and fixed by conductive carbon tape. Secondary and back scattered electron imaging was performed under high vacuum conditions at an accelerating voltage of $10 \mathrm{kV}$ using Everheart-Thornley (ETD) and solid-state detector (SSD). The chemical composition of the electrodes before and after modification was studied by X-ray spectral analysis (EDAX Genesis V6.04) at $10 \mathrm{kV}$ accelerating voltage and $100 \mathrm{~s}$ acquisition time.

\subsection{Transmission Electron Microscopy (TEM)}

For TEM study, a droplet of the sample solution was placed onto a holey carbon film (type S147-4, Plano, Wetzlar, Germany) and dried under ambient conditions. Bright field TEM imaging was performed at $200 \mathrm{kV}$ accelerating voltage using a JEOL (Akishima, Tokyo, Japan) JEM-2100 $\mathrm{LaB}_{6}$ electron microscope (HR pole piece) equipped with a Gatan (Pleasanton, CA, United States) Orius SC1000 CCD camera.

\subsection{Elemental and Phase Analysis}

To control the composite content and phase transformation, XRD analysis performed on a DRON-3.0 (IC Bourevestnik, St. Petersburg, Russia) was used. Thermogravimetry (TGA) coupled differential scanning calorimetry (DSC) was carried out on a STA 409 Luxx (NETZSCH, Selb, Germany), operated at the following conditions: heating rate from $35^{\circ} \mathrm{C}$ to $500{ }^{\circ} \mathrm{C}$, with a step of $5^{\circ} \mathrm{C} / \mathrm{min}$. A Vario EL cube (Elementar GnbH, Langenselbold, Germany) was used for elemental CHNS + O analysis.

\subsection{Electrochemical Studies}

To estimate the electroactivity of the composites, a set of experiments utilizing conventional three-electrode electrochemical cell $(15 \mathrm{~mL})$ was used. The cell consisted of a glassy carbon electrode, GCE, in disk form $\left(0.07 \mathrm{~cm}^{2}\right)$ as a working electrode, a saturated silver chloride electrode separated from working electrolyte via a double frit as a reference and platinum wire counter electrodes. Inert gas (argon) or 100\% oxygen atmospheres were maintained by Schlenk's line. A dry powder of composite was used for modification of a GCE by a drop-coating procedure. 
For ink preparation, an aliquot $(0.4 \mu \mathrm{g})$ of a powder (or pure CuI used as a reference system) was re-dispersed in a water-ethanol $(1: 1 \mathrm{v} / \mathrm{v})$ mixture with a Nafion suspension (Nafion DE1020) as a binding agent. All measurements involved GCE were carried out on a potentiostat Autolab PGSTAT 101 (Metrohm AG, Germany).

To compare the electrochemical response obtained from CuI-PPy modified GCE, $\mathrm{SPE} / \mathrm{GO}$ and $\mathrm{SPE} / \mathrm{TiO}_{2}$ systems were used. A final CuI-PPy solution was dropped on the surface of the working electrodes and dried at $60{ }^{\circ} \mathrm{C}$ for $1 \mathrm{~h}$. The electrochemical response of CuI-PPy modified SPEs was recorded in CV mode on the one-channel biologic Potentiostat PalmSens4 (PalmSens, Utrecht, The Netherlands). To confirm the modification procedure of $\mathrm{SPE} / \mathrm{GO}$ and $\mathrm{SPE} / \mathrm{TiO}_{2}$ by CuI-PPy, the $\mathrm{CV}$ s curves were obtained by placing a $150 \mu \mathrm{L}$ droplet of pure phosphate buffer $(\mathrm{pH} 7)$ over all three electrodes and scanning at $20 \mathrm{mV} / \mathrm{s}$ from $-0.2 \mathrm{~V}$ to $0.2 \mathrm{~V}$ (unless stated otherwise). To explore the stability of $\mathrm{CuI}$ entrapped into the polymer matrix, the anodic limit was extended from $0.2 \mathrm{~V}$ to $0.8 \mathrm{~V}$.

\section{9. $\mathrm{pH}$ Measurements}

The $\mathrm{pH}$ of the solutions was controlled by a HORIBA LAQUATWIN PH-22 $\mathrm{pH}$ meter (MMM tech support GmbH\&Co KG, Berlin, Germany). The $\mathrm{pH}$ meter was calibrated in a series of buffer solutions in the range of 1-13.

\section{Results}

\subsection{Fundamental Chemical Aspects and Optimization of the Synthesis Conditions}

According to the methodology reported in [32], the formation of CuI-polypyrrole, CuI-PPy, composite from the multicomponent solution of copper (II) ions, iodide-anions (or molecular iodine) and pyrrole monomer can be realized as two subsequent synthetic routes:

$$
\begin{gathered}
\mathrm{Cu}^{2+}+\mathrm{Py}+\mathrm{KI}=\frac{1}{\mathrm{n}}[\mathrm{PPy}]_{\mathrm{n}} \cdot \mathrm{CuI}+\mathrm{H}^{+}+\mathrm{K}^{+} \\
\mathrm{Cu}^{2+}+2 \mathrm{KI}=\mathrm{CuI}+\frac{1}{2} \mathrm{I}_{2}+2 \mathrm{~K}^{+} \\
\mathrm{Cu}^{2+}+\mathrm{Py}+\frac{1}{2} \mathrm{I}_{2}=\frac{1}{\mathrm{n}}[\mathrm{PPy}]_{\mathrm{n}} \cdot \mathrm{CuI}+\mathrm{H}^{+}
\end{gathered}
$$

Based on the first synthetic route (reaction 1), the interaction between copper (II) and iodide anions leads to the formation of copper (I) iodide and molecular iodine (1a) followed by oxidation of the pyrrole monomer to polypyrrole. In this route the growth of $\mathrm{CuI}$ nuclei is restricted by the polypyrrole chains. In contrast, in a synthetic reaction 2, a pyrrole monomer is oxidized directly by the iodine resulting in the formation of polypyrrole chains and iodide anions. The latter interacts with copper (II) ions and induces the formation of copper (I) iodide crystals. Notably, regardless of the synthetic approach, two partial reactions occur in each route: (A) interaction of copper (II) and iodide anions that leads to $\mathrm{CuI}$ and iodine formation and (B) pyrrole oxidation by a molecular iodine (or $\mathrm{I}_{3}{ }^{-}$anion which presented in solution of $\mathrm{I}^{-}$and $\mathrm{I}_{2}$ components) with a production of polypyrrole oligomers and $\mathrm{I}^{-}$.

Since the rate of CuI building is very fast (takes seconds) in comparison with the polypyrrole generation (hours), the most important task was to control the rate of partial reaction (1a). To this end, both, i.e., the concentrations of reagents and the addition sequence, were optimized in the next step. In addition, in several experiments (samples $2-5$, Table 1) the period of copper sulphate addition to the iodine reaction mixture by route 1 was varied, and the impact of this procedure on the product yield was evaluated.

The initial concentration of reagents in the synthesis performed by reaction (1) (Table 1) was chosen empirically. The concentrations of reagents were consistently diminished to avoid a fast coagulation of the copper iodide crystals in solution. For the reaction (2) the addition of copper sulfate to the reaction mixture was performed in $4 \mathrm{~h}$ after Py and iodine were mixed to create an excess of the oligomers in the solution. The duration of 
the synthesis by reaction (2) was at least two orders of magnitude higher as compared to reaction (1).

Regardless of the used preparation route, to estimate the completeness of reaction and to validate the impact of contact time on the formation of the composites, a specific $\mathrm{UV}-\mathrm{Vis}$ protocol was proposed. The $\mathrm{Cu}(\mathrm{II})$ and iodine as the initial reagents have some characteristic bonds in the visible and near-infrared range. In contrast, the iodide anion and pyrrole monomer can absorb at $200 \mathrm{~nm}$; see Figure 1a. The absorbance of iodine has been established at 300, 360 and $450 \mathrm{~nm}$. After the beginning of the reaction, the absorbance of the initial components decreases (Figure $1 a, b$ ). At the same time, the absorbance of the polypyrrole oligomers, recorded at 400-500 and 700-900 nm, increases. The precipitation of the formed composites induces a decrease in the absorbance of the entire spectrum (see Figure 1b, curves 1 and 2). Several hours after the start of the experiment, the absorbance of the whole spectrum increases (Figure 1b, curves 2-5), most probably due to colloids formation in the reaction mixture. However, after $24 \mathrm{~h}$, the absorbance of the entire spectrum significantly decreases as a result of precipitation of the produced composites (see Figure 1b, curve 6).
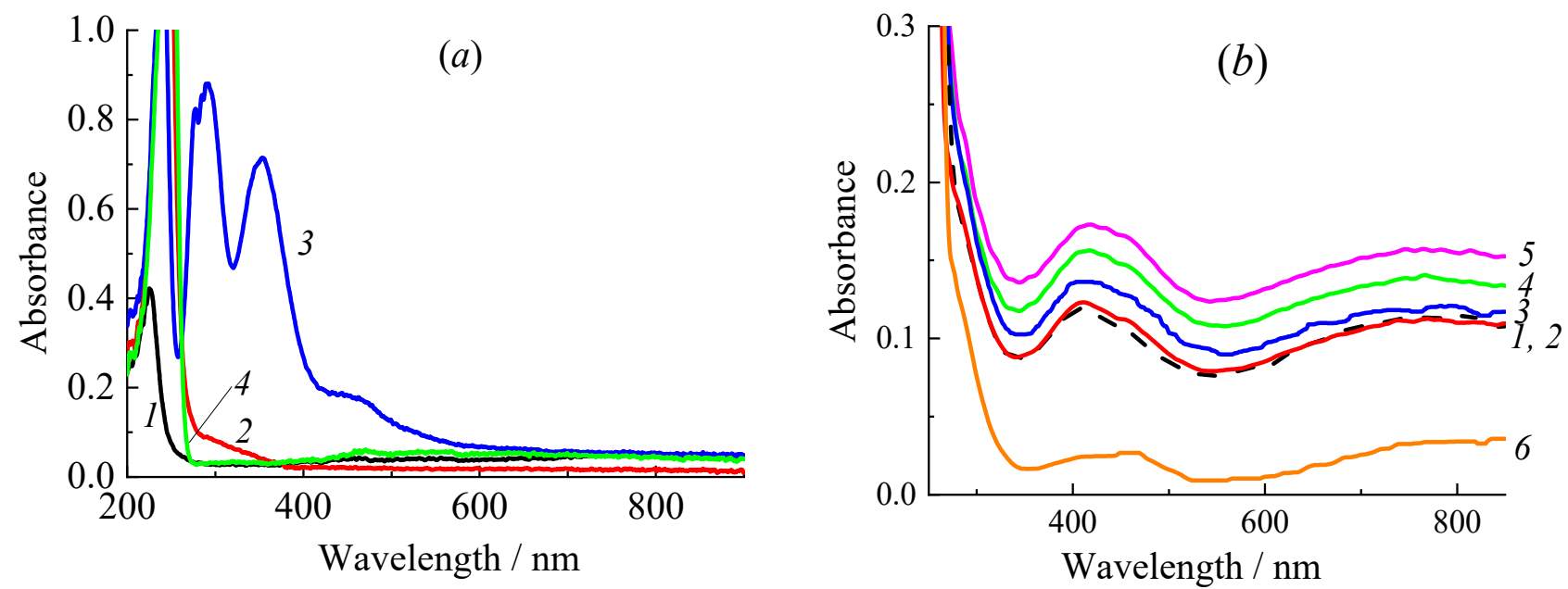

Figure 1. Representative UV-Vis spectra obtained for (a) individual components of the synthesis: $1-1.5 \mathrm{mM} \mathrm{CuSO}_{4}$, 2-10 mM Py, 3-0.5 $\mathrm{mM} \mathrm{I}_{2}, 4-3 \mathrm{mM} \mathrm{KI}$; (b) the multiple mixture at the initial (1) synthesis time and after a complete reaction route (shown for the sample 4 as a case study): $2-1 \mathrm{~h}, 3-2 \mathrm{~h}, 4-3.5 \mathrm{~h}, 5$-after $5.5 \mathrm{~h}, 6$ - $24 \mathrm{~h}$.

The impact of experimental conditions, i.e., contact time and the ratio of reacting compounds on the CuI product yield (Table 1) was validated by elemental HCNS-O, TGA and EDX analysis. All these methods gave similar results (data are not shown). Remarkably, the yield of the formed composites was varied depending on the synthetic procedure from $14 \%$ to $90 \%$ for the first reaction and about $3 \%$ for the second reaction.

Notably, the proposed synthesis process was conducted as successive chemical reactions in one reactor. As a result, one-pot synthesis of CuI-PPy helps to avoid a sequence of separation and purification stages of the intermediate products. In addition, it should be highlighted that, regardless of the reaction sequence, the proposed synthesis of CuI-PPy hybrid composites meets all requirements of Green chemistry, viz., the usage of green solvents during manufacture and formation of bio-friendly end-products.

\subsection{Characterization of the Hybrid Composites}

Next, the surface morphology of the composites obtained by different preparation routes (Table 1) was studied by SEM analysis. The inspection of SEM images indicates that the morphology of the generated composites was very similar it terms of CuI formation, regardless of the used fabrication approach; see Figure 2. Briefly, the obtained surfaces exhibited by inorganic crystals with an average size from $400 \mathrm{~nm}$ to $4 \mu \mathrm{m}$ mixed with the 
polypyrrole globules. However, the samples obtained by route (1) more likely represent a two-phase mixture than composites (see ESI, Figure S1). On the contrary, the samples obtained by route (2) represent a polymer framework with crystals inclusion 200-400 nm in diameter (shown for sample 7 as a case study). EDX spectrum recorded from the crystals incorporated into the polymer matrix of sample 7 indicates the formation of CuI; see ESI, Figure S2.
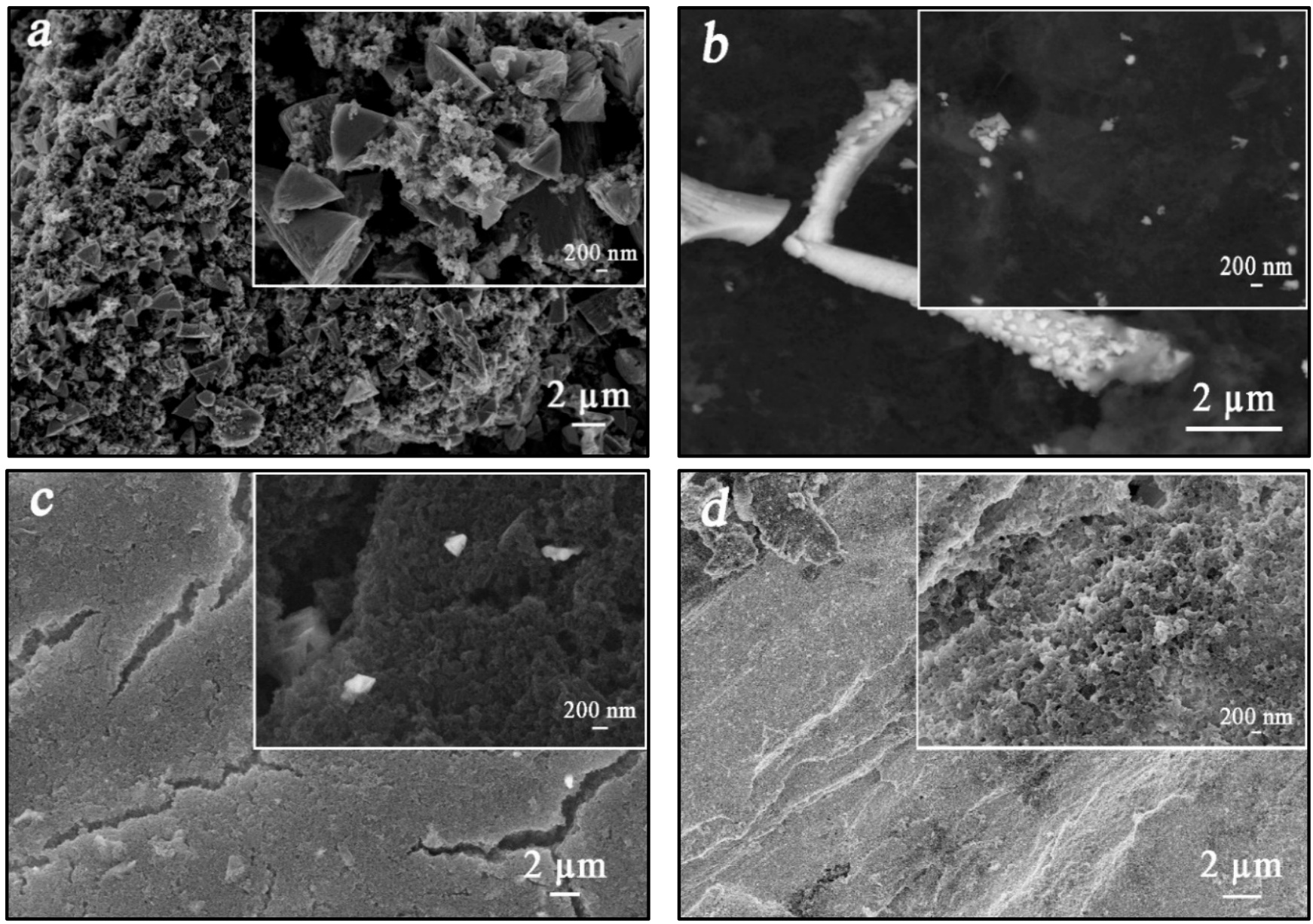

Figure 2. SEM images of CuI-PPy composites: (a) sample 3, (b) sample 4, (c) sample 6, (d) sample 7. The description of samples is specified in Table 1.

The subsequent TEM analysis of the samples 4 and 7 (Figure 3) revealed inorganic inclusions with a size of $5-10 \mathrm{~nm}$ inside the polypyrrole globules. Electron diffraction in selected area, SAED, recorded for sample 7 shows the diffraction pattern corresponding to a short-range ordering of the obtained crystals. We assume that these crystals are nanosized $\mathrm{CuI}$ nanoparticles distributed inside the polypyrrol globules. This result was in line with a dependency obtained for palladium-modified PPy hybrid nanocomposite [31].

Furthermore, XRD analysis of CuI-PPy clearly indicates the existence of the crystalline structure, i.e., marshite $\mathrm{CuI}$ within the samples (Figure 4). The XRD pattern obtained from sample 7 exhibited by stretched reflection of $<111>$ face. The coherent-scattering region size estimated from $<111>$ reflection was $\sim 37 \mathrm{~nm}$ for sample 3 , about $\sim 30 \mathrm{~nm}$ for sample 6 and $\sim 11 \mathrm{~nm}$ for sample 7 , respectively. 

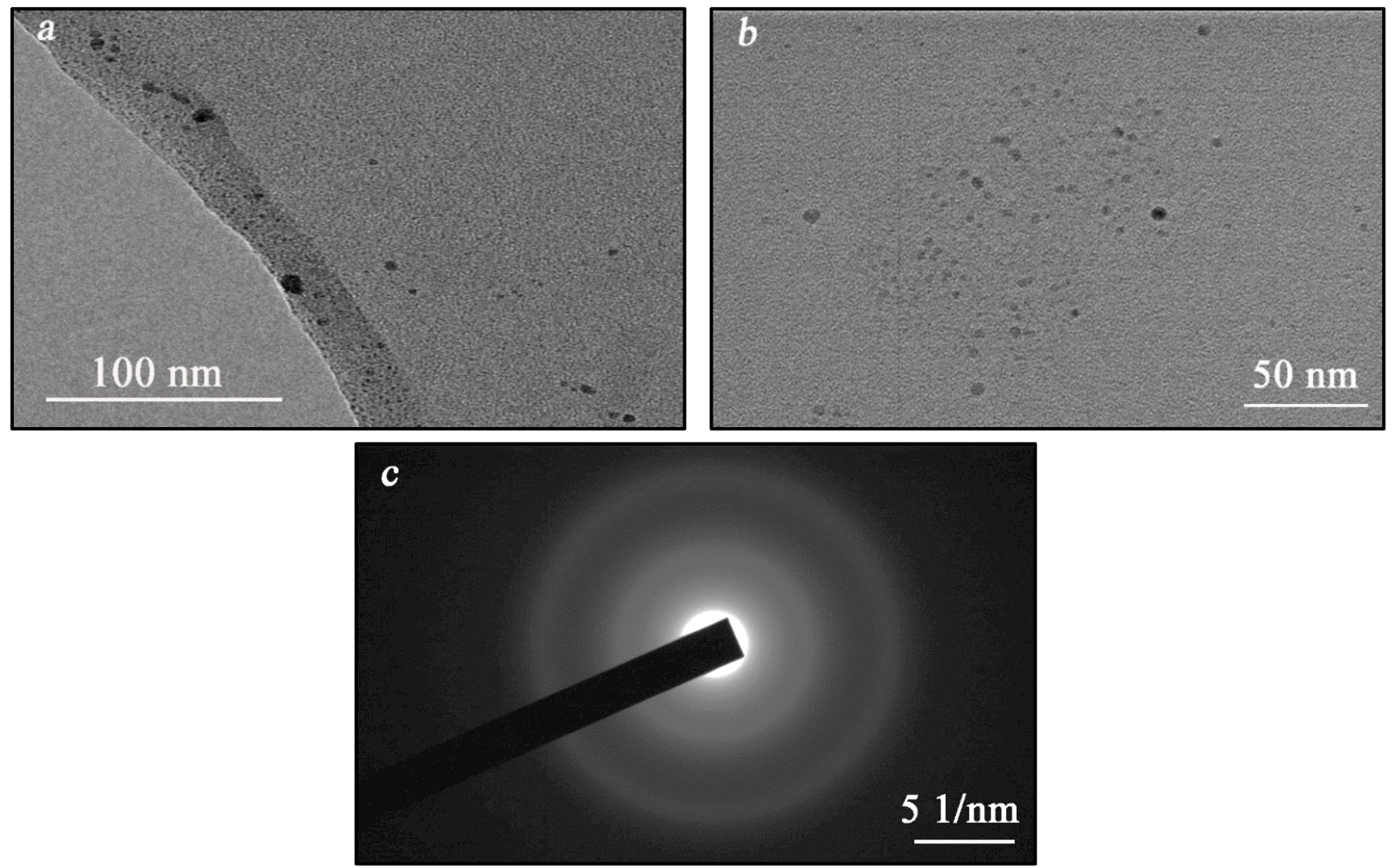

Figure 3. TEM images of CuI-PPy rinsed samples: (a) sample 4, (b) sample 7, (c) electron diffraction in selected area (SAED) of sample 7 .

Thus, by tandem of SEM/EDX, TEM and XRD analyses, we approved the formation of the crystalline $\mathrm{CuI}$ within the hybrid material. However, the residual part (assumed as a polymer network) remained unclear.

To this end, the synthesized samples were investigated by LDI-MS, according to a previously reported protocol [37]. The mass spectrum obtained from the hybrid sample in negative ionization mode, clearly exhibited by $\mathrm{CN}^{-}$, corresponded repeatable ion species, Figure 5.

Importantly, the formation of $\mathrm{CN}^{-}$species indicates the presence of a polymer in the hybrid layer. This result was in agreement with a dependency found by atmospheric pressure LDI-MS for other polymer-based materials. Thus, for Nafion- and Triton-based polymer films, the formation of repeatable $\mathrm{CF}_{2}^{-}$[37] and $\mathrm{C}_{2} \mathrm{H}_{4} \mathrm{O}^{-}$[38] units was reported. Notably, no characteristic $\mathrm{CN}^{-}$-corresponding patterns were recorded from Py dropped on the solid surface indicating the absence of polymerization; see ESI, Figure S3.

The presence of a $\mathrm{CN}^{-}$group in the mass spectra we used as a labeling agent of polypyrrole-based hybrid structures, thus simplifying data analysis and material characterization. Moreover, in full scan recorded from the surface of $\mathrm{SPE} / \mathrm{TiO}_{2}$ modified by CuI-PPy the presence of $\mathrm{CuI}$ entrapped into the iodine-polymer framework, i.e., $\mathrm{m} / \mathrm{z}[\mathrm{CuI}+\mathrm{I}]^{-}$was clearly seen, Figure 6. 

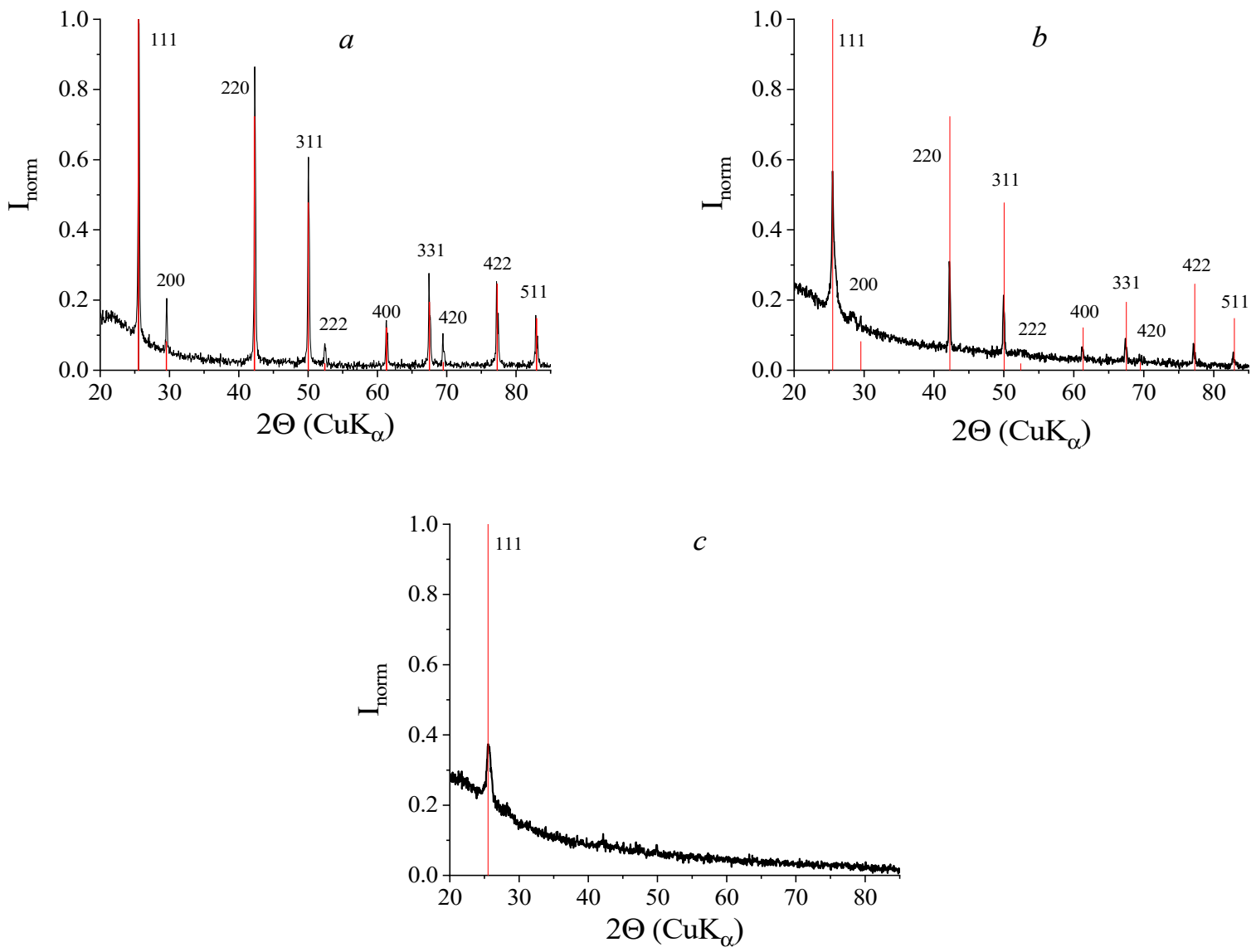

Figure 4. XRD-pattern recorded from the rinsed CuI-PPy samples: (a)-1-5, (b)-6, (c) -7. Bars corresponded to CuI structure in accordance with JCPDF $N^{\circ} 83-1137$. Note: the halo in the area of $20^{\circ}$ is corresponding to the presence of amorphous PPy.

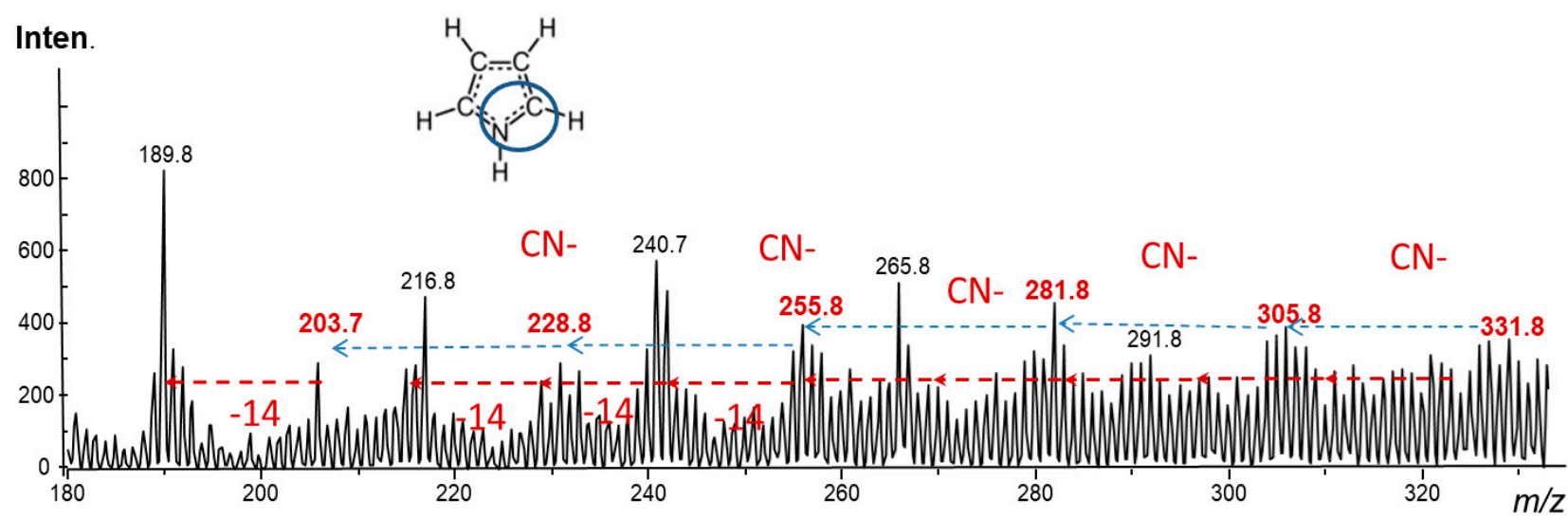

Figure 5. Laser desorption ionization mass spectrometry (LDI-MS) spectra recorded from CuI-PPy deposited by drop coating on the surface of SPE modified by graphene oxide (SPE/GO), laser fluence $40 \%$. Note: LDI-MS analysis was performed at the atmospheric pressure conditions (AP-MALDI ion source); all experiments were performed in a triplicate with the same results. Signal to noise ratio (SNR) determined for $\mathrm{CN}^{-}$species at the used experimental conditions was in the range from 10:1 to 12:1. 


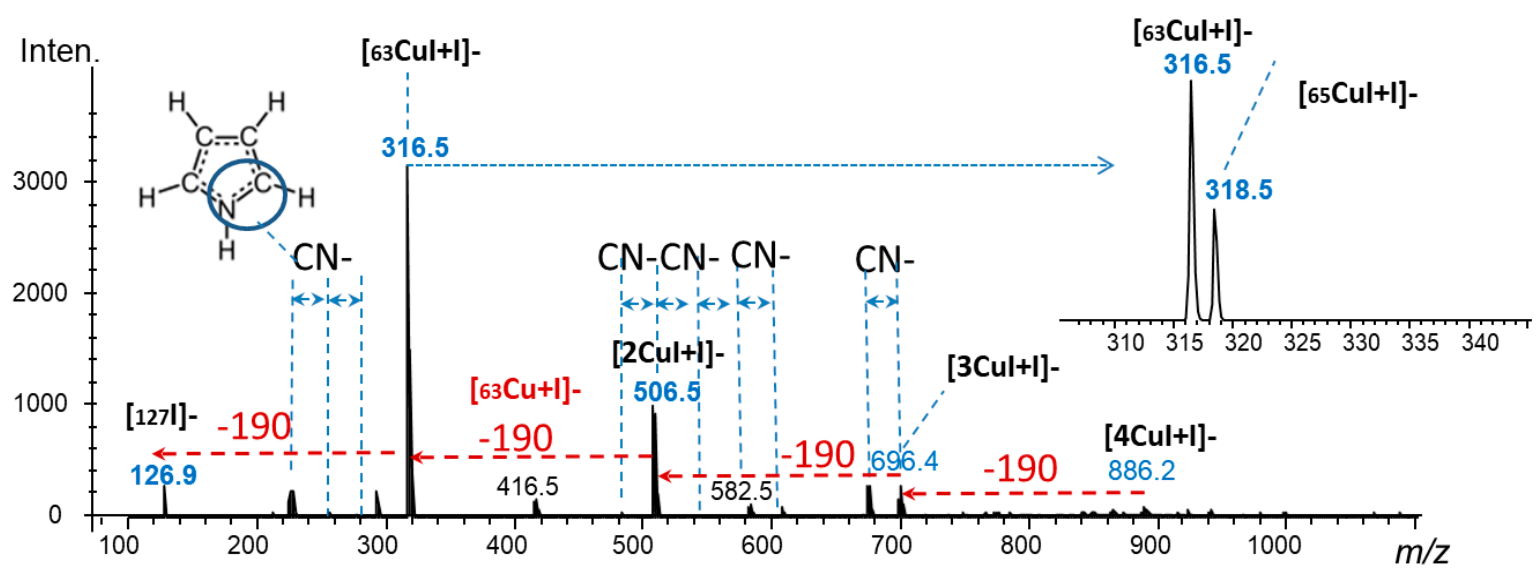

Figure 6. LDI-MS full scan recorded from CuI-PPy deposited by drop coating on the surface of SPE modified by TiO ${ }_{2}$ nanotubes $\left(\mathrm{SPE} / \mathrm{TiO}_{2}\right)$, laser fluence $40 \%$. Note: all experiments were performed in a triplicate with the same results.

The mass spectra received from $\mathrm{SPE} / \mathrm{TiO}_{2}$ modified by CuI-PPy exhibited by repeatable copper iodine adducts $[\mathrm{nCuI}+\mathrm{I}]^{-}$with typical copper isotope patterns, viz., ${ }_{3} \mathrm{Cu}$ and ${ }_{65} \mathrm{Cu}$ in the ratio of $69.15 \%$ and $30.85 \%$, respectively. This fact might be essential to provide the conductivity of the formed hybrid material for the subsequent electrochemical experiments (see Section 3.4). Finally, MS-MS analysis of repeatable peaks corresponding to the copper iodine adducts $[\mathrm{nCuI}+\mathrm{I}]^{-}\left(\right.$at $\mathrm{m} / \mathrm{z} 506.5$ and 316.4 for $[2 \mathrm{CuI}+\mathrm{I}]^{-}$and $\left.[\mathrm{CuI}+\mathrm{I}]^{-}\right)$has confirmed the formation of $\left[{ }_{63} \mathrm{Cu}+\mathrm{I}\right]^{-}$and $\left[{ }_{65} \mathrm{Cu}+\mathrm{I}\right]^{-}(\mathrm{m} / \mathrm{z} 190$ and 192) fragments as the most abounded species (see ESI, Figure S4).

\subsection{Morphological Reproducibility and Storage Stability of CuI-PPy Composite}

To estimate the reproducibility of the formed hybrid after dropping and drying of CuIPPy on different solid substrates in comparison with the rinsed samples, the morphological structure of the composites deposited on $\mathrm{SPE} / \mathrm{GO}$ and $\mathrm{SPE} / \mathrm{TiO}_{2}$ was investigated. As it is seen from SEM images, the morphology and size of the formed CuI distributed across PPy layer dropped on SPEs was very similar to that obtained for the rinsed samples regardless of the used preparation route, Figure 7. In other words, the reproducibility in the morphological structure of the composites after drying on the solid templates can be guaranteed.
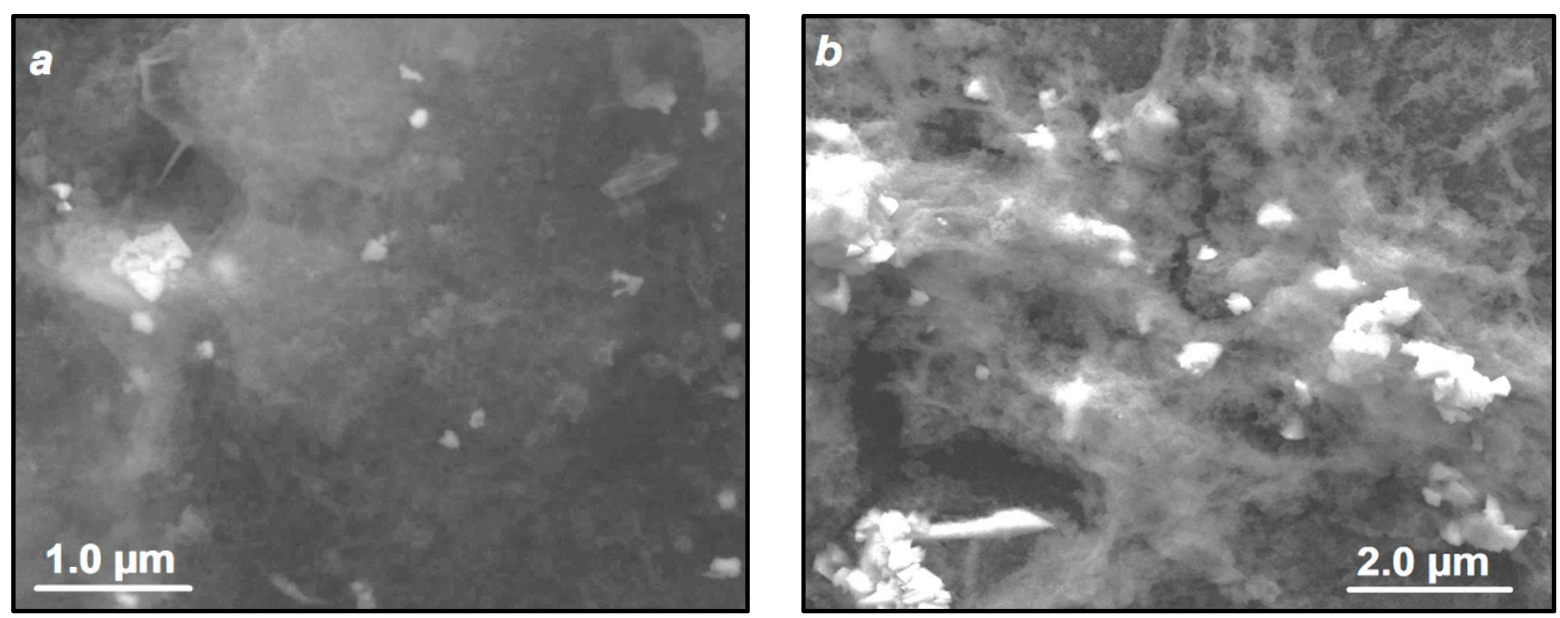

Figure 7. SEM images of the hybrid CuI-PPy structures (sample 4, route 1) obtained from modified SPE/GO (a) and $\mathrm{SPE} / \mathrm{TiO} 2(\mathbf{b})$.

One of the possible problems associated with the usage of multicomponent solutions is that their long-term stability is often very poor. In this regard, on the next step, we inves- 
tigated the stability of the multicomponent solution used for CuI-PPy synthesis after the storage period. Surprisingly, SEM and TEM studies performed for the rinsed liquid sample directly after preparation and after its storage for 6 weeks did not reveal significant changes; see Figure 8. It means that this multicomponent solution can be used as a conductive ink without any specific stabilizers even after storage (see ESI, Figure S5). The stability of the ink solution can explain the above-observed reproducibility in the morphological structure of the hybrid composites (Figure 7). These two effects (morphological reproducibility and storage stability) create good preconditions for the employment of this ink for fabrication of ultimate functional devices, i.e., chemical sensors (see the next section).
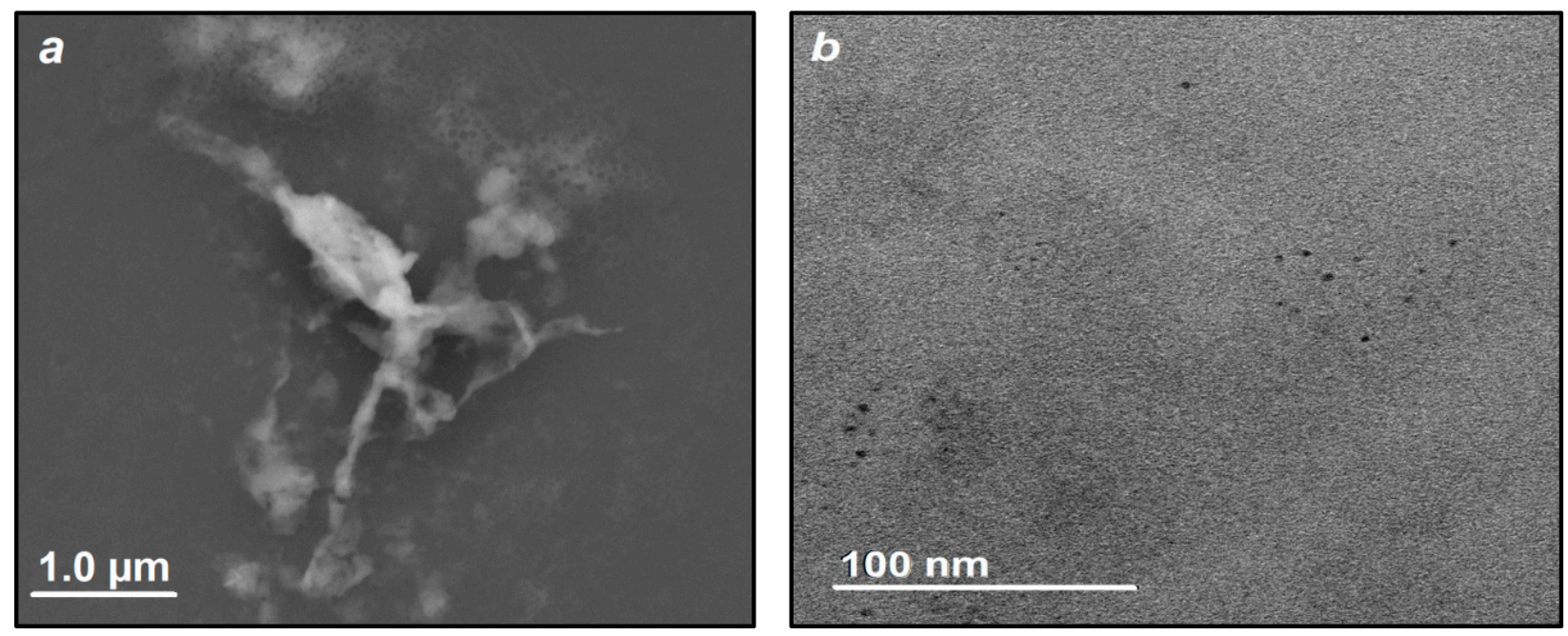

Figure 8. (a) SEM image of the CuI-PPy composite (sample 4) formed by the use of the ink stored for 6 weeks; (b) TEM image of the rinsed ink after its storage in darkness in aqueous solution at the ambient conditions during 6 weeks.

\subsection{Electrochemical Performance of CuI-PPy}

3.4.1. Electrochemical Response Estimated on a Glassy Carbon Electrode under Inert Gas and Oxygen Atmospheres

Remarkably, during incorporation of metals and metal-containing structures into the framework of conductive polymers, i.e., PPy, the electrical and thermal conductivity of the fabricated hybrids can be significantly improved [39]. To verify the electroactivity of the designed composites, the electrochemical response of CuI-PPy samples was evaluated in $\mathrm{CV}$ mode first in $0.5 \mathrm{M} \mathrm{H}_{2} \mathrm{SO}_{4}$ under both, i.e., an inert gas and oxygen atmospheres. The response obtained from CuI-PPy composite was compared with a signal received from pure CuI (see Experimental part for the details). From Figure 9, it is seen that the obtained $\mathrm{CV}$ response was typical for the conjugated polymers modified by inorganic electroactive particles [40-43]. The presence of the conjugated polymers in the composite increases the capacitive currents. In contrast, the presence of electroactive inorganic component leads to the appearance of peaks or waves corresponding to electron transfer.

The analysis of CV curves (Figure 9) recorded in the presence of molecular oxygen from the copper iodide (curve 3) and hybrid composite (curve 4) indicated their similar electrochemical behavior. Thus, a cathodic wave beginning at $0 \mathrm{~V}$, assigned to oxygen electroreduction on the surface of copper iodide, and an anodic peak detected at $0.12 \mathrm{~V}$, corresponding to an oxidation process, were recorded. The similar behavior of the cathodic current in the presence of molecular oxygen was reported for copper (II) benzene-1,3,5tricarboxylate and copper (II)-2,2'-bipyridine-benzene-1,3,5-tricarboxylate-based film [44]. The electrocatalytic effect of the produced films was explained in terms of the presence of a $\mathrm{Cu}(\mathrm{II}) / \mathrm{Cu}(\mathrm{I})$ redox-couple.

In our experiments, the electrochemical response obtained from the hybrid composite was more stable from cycle to cycle in oxygen containing solutions as compared to pure $\mathrm{CuI}$. The backward anodic peak current of $\mathrm{CuI}$ decreases each cycle by approximately $10 \%$. 
In contrast, only $4 \%$ decrease of the peak current was observed for CuI-PPy composite from cycle to cycle. Since PPy has been approved to long-term cycling stability [43], the degradation of the obtained CV response from the hybrid composite can be assigned to inorganic component. This result was in agreement with a previously reported dependency found for PPy-based electrode with electromodified copper microparticles [39].

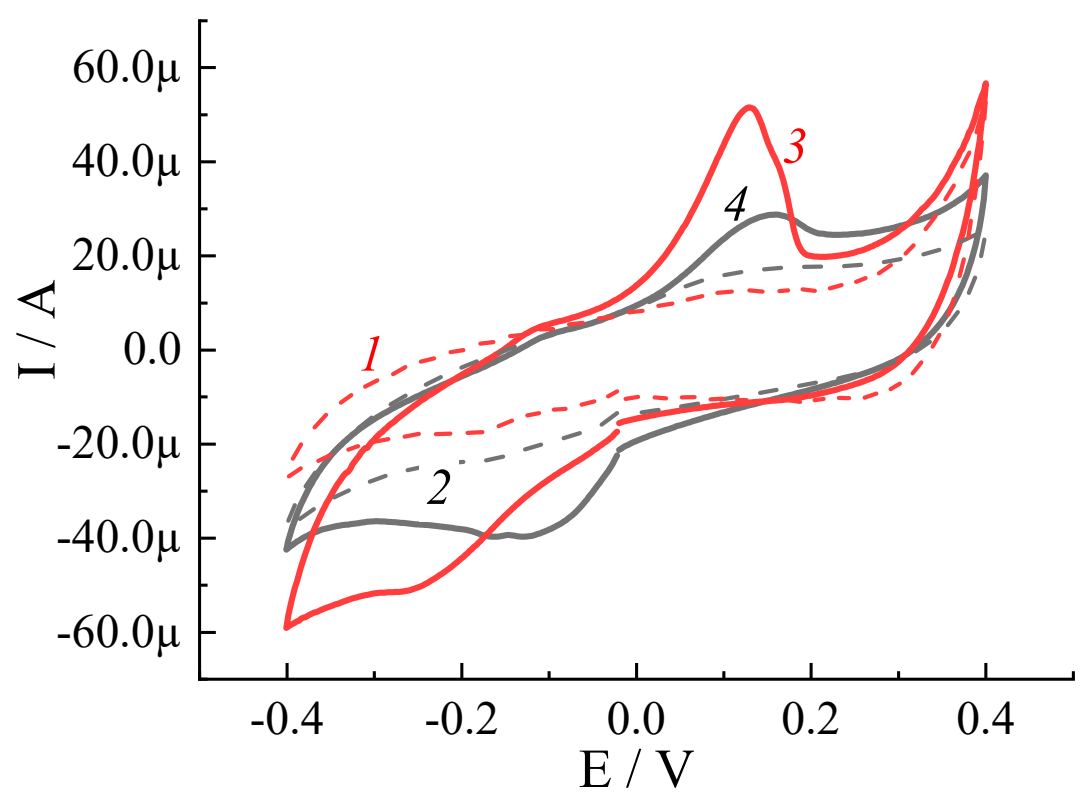

Figure 9. Cyclic voltammetry (CV) curves obtained from glassy carbon electrode (GCE) modified by $(1,3)$ pure $\mathrm{CuI}$ and $(2,4) \mathrm{CuI}-\mathrm{PPy}$ in $0.5 \mathrm{M} \mathrm{H}_{2} \mathrm{SO}_{4}$ under inert $(1,2)$ and oxygen $(3,4)$ atmosphere. $\mathrm{pH} 1$, scan rate $20 \mathrm{mV} / \mathrm{s}$.

According to the literature, the process recorded at the anodic range can correspond to the oxidation of copper (I) or (0) to copper (II) or (I) that is facilitated by hydrogen peroxide, hydroxyl species or other oxygen-containing intermediates formed in the cathodic scan as an intermediate product of oxygen electroreduction. The impact of $\mathrm{OH}$-ions on the oxygen reduction catalyzing by copper (I) compounds was discussed in $[45,46]$.

To analyze the influence of hydroxyl ions on copper (I) oxidation in the present work, the $\mathrm{CV}$ procedure was repeated in $0.01 \mathrm{M} \mathrm{NaOH}$ as a background solution. From the experiment it is seen that the anodic peak obtained from pure $\mathrm{CuI}$ at $0.5 \mathrm{~V}$ and $\mathrm{CuI}-\mathrm{PPy}$ modified GCE at $0.35 \mathrm{~V}$ (Figure 10) corresponds to the oxidation of copper in copper iodide. Obviously, this phenomenon had a similar nature as reported in [28]. It should be highlighted that the presence of hydroxyl-ions in solution facilitates this oxidation process. At the same time, the cathodic peaks observed in CV correspond to the reduction of copper (II) formed during the anodic scan.

Notable, regardless of the preparation route, all obtained CuI-PPy composites demonstrated significant electrochemical response and reproducible electroactive behavior. Hence, a conductive ink consisting of aqueous CuI-PPy solution can be used for modification of the solid surfaces and production of the chemical sensors (see the next section). However, it would be fair to notice that the use of the formed hybrid composite for sensor-related applications can be recommended exclusively in the weak acidic/basic or neutral solutions. In addition, the anodic potential range should not exceed $0.4 \mathrm{~V}$ vs. silver chloride electrode. 


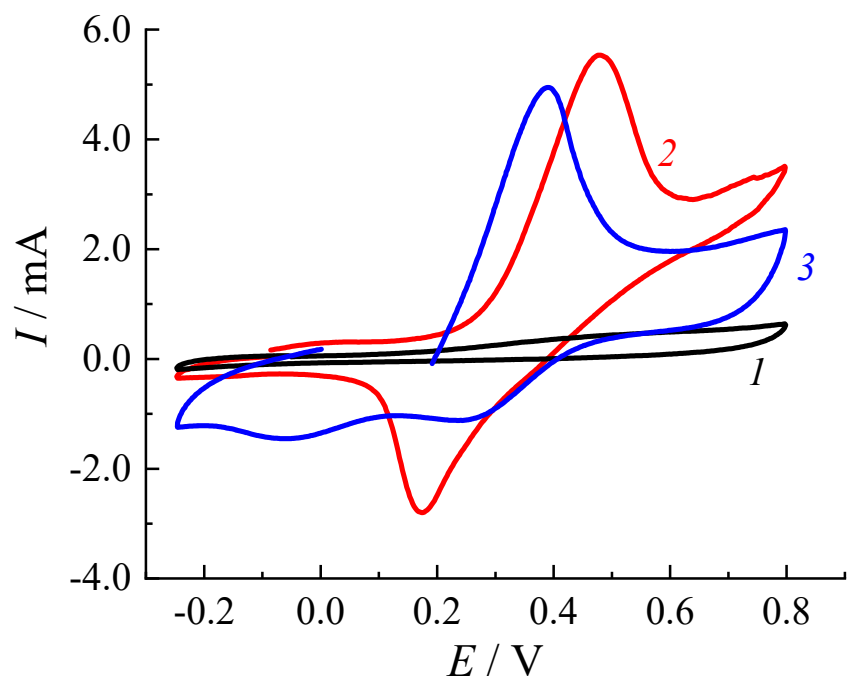

Figure 10. CV curves obtained from (1) GCE modified by (2) pure CuI and (3) CuI-PPy (sample 6) in $0.01 \mathrm{M} \mathrm{NaOH}$. pH 12, scan rate $20 \mathrm{mV} / \mathrm{s}$.

\subsubsection{Electrochemical Performance of CuI-PPy Modified SPEs}

The completeness of the performed modification of SPE/GO and $\mathrm{SPE} / \mathrm{TiO}_{2}$ by CuIPPy was monitored by CV studies; ESI, Figure S6. In general, the electrochemical response recorded in the range $-0.2 \mathrm{~V}$ to $0.2 \mathrm{~V}$ from CuI-PPy modified SPE/GO or SPE/ $\mathrm{TiO}_{2}$ was similar. In both cases, there is a cathodic wave corresponding to an oxygen reduction process. Briefly, CuI-PPy demonstrated the same electrochemical behavior on SPEs as it was detected on the surface of GCE. The shifting of the anodic polarization limit to the range above $0.4 \mathrm{~V}$ leads to the appearance of an anodic wave (consisted of two peaks), corresponding to $\mathrm{CuI}$ oxidation, and a cathodic peak at $+0.38 \mathrm{~V}$, relating to the reduction of copper (Figure 11). The extension of the anodic limit to $+0.8 \mathrm{~V}$ (Figure 10) results in a gradual release of $\mathrm{CuI}$ from the polymer matrix. However, the dissolution of $\mathrm{CuI}$ does not occur when the polarization limit does not exceed 0.4 V, Figure 11.

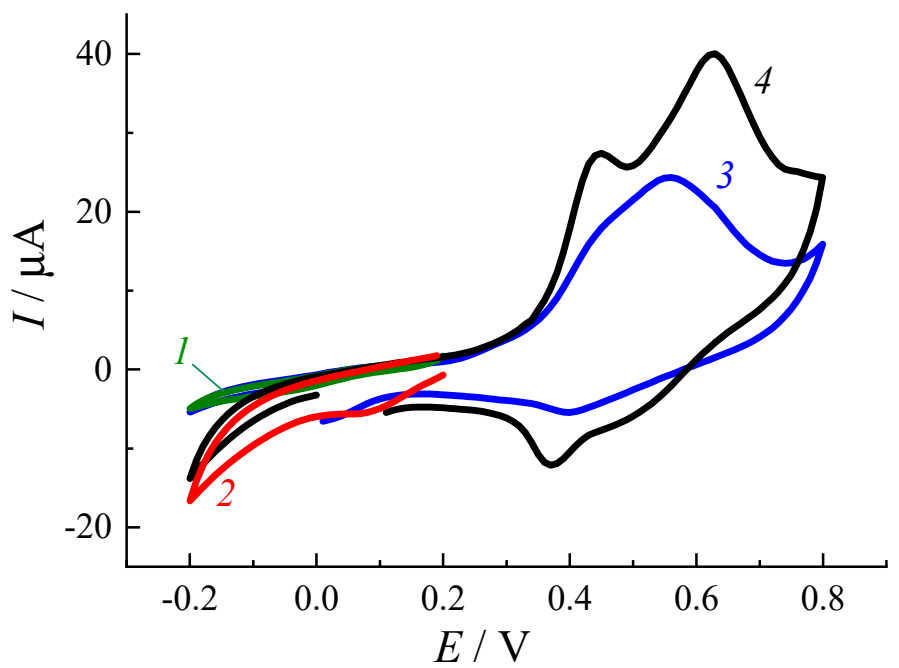

Figure 11. CV curves obtained in buffer $(\mathrm{pH} 7)$ at $20 \mathrm{mV} / \mathrm{s}$ from $(1,3) \mathrm{SPE} / \mathrm{GO}$ and $(2,4) \mathrm{SPE} / \mathrm{TiO}_{2}$ modified by $3 \mu \mathrm{L}$ CuI-PPy (drop coating) at different anodic limits: $1,2-0.2 \mathrm{~V} ; 3,4-0.8 \mathrm{~V}$, respectively.

Hence, with regards to the sensors operational mode, it can be concluded that the optimal potential range should not exceed the range from -0.4 to $0.4 \mathrm{~V}$. 


\subsubsection{Application for Chemical Sensing}

Studies available in literature indicate that modified conductive polymers, viz., PPy are widely used in fuel cells-related research, batteries, super capacitors development and in corrosion protection [40]. However, the electrochemical sensing properties of PPy-based hybrids have been poor exploit. Thus, the 3D PPy-doped mixed-valent $\mathrm{Cu}$ (I) $/ \mathrm{Cu}$ (II) metalorganic composites were exclusively applied for gas sensing, i.e., $\mathrm{O}_{2}, \mathrm{CO}_{2}$, water and organic solvents detection utilizing $[47,48]$ quartz crystal microbalances and thermistorbased methods.

In addition, the presence of I-ions within the framework of the hybrid CuI-PPy composite allows its use in numerous clinical diagnostic-related applications where the biocompatibility is a big issue.

Next, the electrochemical behavior of the fabricated CuI-PPy composite toward sensing of glutaraldehyde (GLU) at pH 8 was explored. GLU is an aggressive carbonyl (-CHO) reagent that possesses unique characteristics and is one of the most effective protein crosslinking reagents [49]. In addition, GLU is crucial to many other applications, i.e., health care industry (used as a $1 \%$ or $2 \%$ aqueous solution activated by an alkaline buffer such as sodium bicarbonate) or biosensors development. Therefore, there is a need for development of easy-to-use assay with a low level of maintenance, low cost and simple hand-held design [50-52].

$\mathrm{CV}$ curves recorded in the range of $-0.4 \mathrm{~V}$ to $0.4 \mathrm{~V}$ in the presence of analyte clearly demonstrate the electrochemical response of the hybrid composite toward GLU sensing; see Figure 12. Thus, the presence of analyte in a buffer solution resulted in the appearance of the anodic peak at $0.15 \mathrm{~V}$ indicating GLU oxidation on the surface of CuI-based composite. It is interesting that cathodic current in the range 0 to $-0.4 \mathrm{~V}$ is also increased.

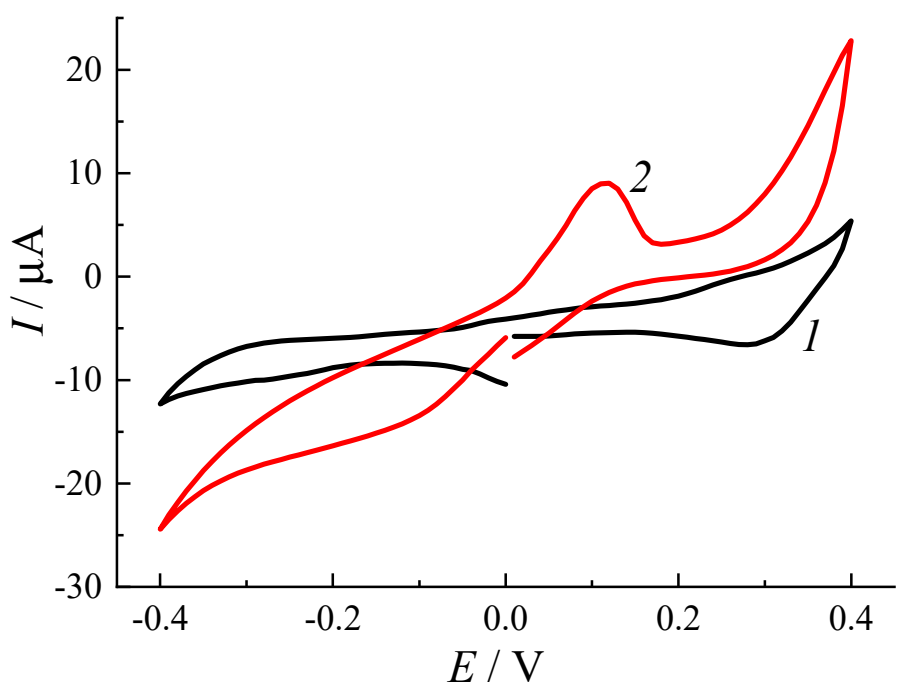

Figure 12. $\mathrm{CV}$ curves obtained at $20 \mathrm{mV} / \mathrm{s}$ from $\mathrm{SPE} / \mathrm{TiO}_{2}$ modified by $3 \mu \mathrm{L}$ CuI-PPy (drop coating) in buffer (1) and 250 ppm of glutaraldehyde (GLU) solution (2) at pH 8.

It would be fair to note that the mechanism of CuI-PPy electrocatalytic activity is not fully understood. We assume that the multivalent ions of copper formed during chemical/electrochemical reaction with the dissolved oxygen can be involved into the oxidation process of aldehyde as reported in [53].

Importantly, here we present a first proof of principle toward the formation of the tailored nanodimensional CuI-PPy-based composites that can be readily implemented as an active layer in chemical sensing technology. The next step in the fabrication of innovative CuI-PPy-based chemical sensors would be the development of specific electrochemical protocols to form the homogeneous films on the surface of solid templates in a fully reproducible and instrumentally controlled manner. Finally, the electrocatalytic mechanism 
underlying the signal readout requires further investigations. We plan to conduct this research in our laboratory in the future.

\section{Conclusions}

Here, we introduced a novel one-pot synthesis of nanodimensional CuI entrapped into a polymer (PPy) matrix. During the course of investigations, it was found that a specific redox reaction between pyrrole and iodine takes place in a solution resulting in the formation of polypyrrole oligomers and iodide anions. Further, the addition of copper (II) into the polypyrrole oligomers and iodide anions-containing mixture leads to the formation of $\mathrm{CuI}$ crystals with an average size of 5-10 $\mathrm{nm}$ incorporated into the polymer framework. It is believed that the particles size of $\mathrm{CuI}$ was reduced from micro- to nanodimensional due to the optimized procedure allowing a controlled pyrrole oxidation in parallel with $\mathrm{CuI}$ formation in a fully chemical reagent- and time-dependent manner. The proposed synthesis was performed in one-pot and meets all principles of Green chemistry.

Moreover, the conductive ink, fabricated according to the optimized synthesis protocol, was applied for the modification of the surface of a glassy carbon and SPE electrodes. During the set of experiments, an advanced electroactivity of the conductive ink was approved that is important for the production of ultimate functional devices, viz., chemical sensors. In addition, the operational read-out mode of CuI-PPy-modified sensors was optimized.

We believe that this study can provide valuable guidance during one-pot synthesis and design optimization of bio-friendly nano-based chemical sensors.

Supplementary Materials: The following are available online at https:/ / www.mdpi.com/2227-904 0/9/3/56/s1, Figure S1: SEM images of the hybrid composite prepared by route 1 . Note: the images show the presence of two phases. Figure S2: EDX spectra recorded from the crystals distributed within the polymer framework (sample 7). Figure S3: LDI-MS spectra recorded from the SPE/GO after spotting of Py $(3 \mu \mathrm{L})$, laser fluence $40 \%$. Figure S4: $\mathrm{MS}^{2}$ mass spectra of $\mathrm{m} / \mathrm{z} 506.5$ (top) and 316.4 (bottom). Collision-induced dissociation (CID) was set at $1 \mathrm{keV}$. Figure S5: Macroscopic images of CuI-PPy ink (a) in initial stage (as prepared) and (b) after $8 \mathrm{~h}$ of storage. Figure S6: CV curves obtained from SPE/GO (top) and SPE/ $\mathrm{TiO}_{2}$ (bottom) modified by $3 \mu \mathrm{L}$ CuI-PPy (drop casting) at $20 \mathrm{mV} / \mathrm{s}$ in phosphate buffer at $\mathrm{pH} 7$.

Author Contributions: A.O.K. performed CuI-PPy synthesis, sample preparations, X-ray and UVvis analyses, and electrochemical tests on glassy carbon electrodes and drafted several parts of original manuscript. N.N.D. was responsible for SEM and EDX studies and data visualization of CuI-PPy samples 1-3, 6, 7. I.I.K. was responsible for TEM and SAED studies of sample 7 and sample preparation. M.K. was responsible for SEM, TEM, and EDX investigations of sample 4, studies related with the ink stability, and reviewing and editing of the original draft. E.V.Z. proposed the entire synthesis conception of the hybrid composites and was responsible for the design of the present study, project administration, wrote, reviewed, and edited the manuscript. Y.E.S. conceptualized LDI-MS methodologies for material characterization, proposed sensing concept, was responsible for design of the study and project administration, wrote, reviewed, and edited the manuscript, and was a part of funding acquisition. All authors have read and agreed to the published version of the manuscript.

Funding: The authors A.O.K. and E.V.Z. performed their work within the framework of the State assignment (number AAAA-A19-119061890019-5). The research of Y.E.S. is funded by the Deutsche Forschungsgemeinschaft (DFG, German Research Foundation, project 427949628).

Acknowledgments: The authors would like to thank German-Russian Interdisciplinary Science Center (G-RISC project) for the support and initiation of collaboration between University of Saarland (Germany) and Institute of Problems of Chemical Physics RAS (Moscow region, Russia).

Conflicts of Interest: The authors declare no conflict of interest. 


\section{References}

1. Sekkal, W.; Zaoui, A.; Laref, A.; Certier, M.; Aourag, H. Molecular dynamics simulation of CuI using a three-body potential. J. Phys. Condens. Matter. 2000, 12, 6173-6182. [CrossRef]

2. Apsana, G.; George, P.P.; Devanna, N.; Yuvasravana, R. One-Step green synthesis, characterization, optical, and photocatalytic properties of metal iodide (MI, M = Ag and Cu) nanoparticles. J. Bionanoscience 2018, 12, 191-199. [CrossRef]

3. Christians, J.A.; Fung, R.C.M.; Kamat, P.V. An inorganic hole conductor for Organo-lead halide perovskite solar cells. Improved hole conductivity with copper iodide. J. Am. Chem. Soc. 2014, 136, 758-764. [CrossRef] [PubMed]

4. Sun, M.; Hu, J.; Zhai, C.; Zhu, M.; Pan, J. A p-n heterojunction of CuI/ $\mathrm{TiO}_{2}$ with enhanced photoelectrocatalytic activity for methanol electro-oxidation. Electrochim. Acta 2017, 245, 863-871. [CrossRef]

5. Wang, J.J.; Chen, C.; Chen, W.G.; Yao, J.S.; Yang, J.N.; Wang, K.H.; Yin, Y.C.; Yao, M.M.; Feng, L.Z.; Ma, C.; et al. Highly Luminescent Copper Iodide Cluster Based Inks with Photoluminescence Quantum Efficiency Exceeding 98\%. J. Am. Chem. Soc. 2020, 142, 3686-3690. [CrossRef] [PubMed]

6. Cha, J.H.; Jung, D.Y. Air-Stable Transparent Silver Iodide-Copper Iodide Heterojunction Diode. ACS Appl. Mater. Interfaces 2017, 9, 43807-43813. [CrossRef]

7. Prokopenko, S.L.; Mazurenko, R.V.; Gunja, G.M.; Abramov, N.V.; Makhno, S.M.; Gorbyk, P.P. Electrophysical properties of polymeric nanocomposites based on cobalt and nickel ferrites modified with copper iodide. J. Magn. Magn. Mater. 2020, 494, 165824. [CrossRef]

8. Crisp, S.; Meddle, D.W.; Nunan, J.M.; Smith, A.F. A copper (I) iodide paper for the detection and determination of the concentration of mercury vapour in the workplace atmosphere. Analyst 1981, 106, 1318-1325. [CrossRef]

9. Wang, Y.; Yang, Q.; Yang, L.; Shi, J.; Zhang, M. CuI/TBAB as a novel efficient catalytic system for Heck reaction in water. RSC Adv. 2013, 3, 21251-21255. [CrossRef]

10. Wang, Y.; Zhang, M. Schiff Base/CuI as a Novel Efficient Catalyst System for Cu-Catalyzed Heck Reaction in Water. ChemistrySelect 2019, 4, 9673-9676. [CrossRef]

11. Lee, V. Application of copper (I) salt and fluoride promoted Stille coupling reactions in the synthesis of bioactive molecules. Org. Biomol. Chem. 2019, 17, 9095-9123. [CrossRef]

12. Zhang, C.; Zhan, Z.; Lei, M.; Hu, L. Ullmann-type C-N coupling reaction catalyzed by CuI/metformin. Tetrahedron 2014, 70, 8817-8821. [CrossRef]

13. Xie, J.; Zhu, X.; Huang, M.; Meng, F.; Chen, W.; Wan, Y. Pyrrole-2-carbohydrazides as Ligands for Cu-Catalyzed Amination of Aryl Halides with Amines in Pure Water. Eur. J. Org. Chem. 2010, 2010, 3219-3223. [CrossRef]

14. Gao, S.; Li, Z.; Jia, X.; Jiang, K.; Zeng, H. Bioinspired synthesis of well faceted CuI nanostructures and evaluation of their catalytic performance for coupling reactions. Green Chem. 2010, 12, 1442-1447. [CrossRef]

15. Kwong, F.Y.; Klapars, A.; Buchwald, S.L. Copper-catalyzed coupling of alkylamines and aryl iodides: An efficient system even in an air atmosphere. Org. Lett. 2002, 4, 581-584. [CrossRef] [PubMed]

16. Ma, D.; Cai, Q.; Zhang, H. Mild method for ullmann coupling reaction of amines and aryl halides. Org. Lett. 2003, 5, 2453-2455. [CrossRef]

17. Tao, C.Z.; Liu, W.W.; Sun, J.Y.; Cao, Z.L.; Li, H.; Zhang, Y.F. 3-acetylcoumarin as a practical ligand for copper-catalyzed C-N coupling reactions at room temperature. Synthesis 2010, 8, 1280-1284. [CrossRef]

18. Yong, F.F.; Teo, Y.C. Efficient ligand-free copper-catalyzed arylation of aliphatic amines. Synlett 2010, 3, 3068-3072. [CrossRef]

19. Kumar, M.; Bhatt, V.; Nayal, O.S.; Sharma, S.; Kumar, V.; Thakur, M.S.; Kumar, N.; Bal, R.; Singh, B.; Sharma, U. CuI nanoparticles as recyclable heterogeneous catalysts for C-N bond formation reactions. Catal. Sci. Technol. 2017, 7, 2857-2864. [CrossRef]

20. Li, J.H.; Li, J.L.; Wang, D.P.; Pi, S.F.; Xie, Y.X.; Zhang, M.B.; Hu, X.C. CuI-catalyzed Suzuki-Miyaura and Sonogashira cross-coupling reactions using DABCO as ligand. J. Org. Chem. 2007, 72, 2053-2057. [CrossRef]

21. Wang, S.; Wang, M.; Wang, L.; Wang, B.; Li, P.; Yang, J. CuI-catalyzed Suzuki coupling reaction of organoboronic acids with alkynyl bromides. Tetrahedron 2011, 67, 4800-4806. [CrossRef]

22. Zhang, H.-F. Copper-catalyzed Ligand-Free Suzuki-Miyaura Coupling Reaction of Aryl Halides with Arylboronic Acid. J. Med. Chem. Sci. 2019, 2, 47-49. [CrossRef]

23. Alavinia, S.; Ghorbani-Vaghei, R.; Rakhtshah, J.; Seyf, J.Y.; Arabian, I.A. Copper iodide nanoparticles-decorated porous polysulfonamide gel: As effective catalyst for decarboxylative synthesis of N-Arylsulfonamides. Appl. Organomet. Chem. 2020, 34. [CrossRef]

24. Solgi, S.; Ghorbani-Vaghei, R.; Alavinia, S. Application of copper iodide nanoparticles immobolized porous polysulfonamide gel as an effective nanocatalyst for synthesis of aminoindolizines. J. Porous Mater. 2020, 28, 289-298. [CrossRef]

25. Ezzatzadeh, E.; Hossaini, Z.; Moradi, A.V.; Salimifard, M.; Abad, S.A.F. Copper iodide and zno nanoparticles catalyzed multicomponent synthesis of 1,3-cyclopentadiene: Study of antioxidant activity. Can. J. Chem. 2019, 97, 270-276. [CrossRef]

26. Mallick, S.; Mukhi, P.; Kumari, P.; Mahato, K.R.; Verma, S.K.; Das, D. Synthesis, Characterization and Catalytic Application of Starch Supported Cuprous Iodide Nanoparticles. Catal. Lett. 2019, 149, 3501-3507. [CrossRef]

27. Dutta, P.K.; Dhar, B.; Sen, S. Aerobic oxidative amidation of alkynes using titanium oxide encapsulated cuprous iodide nanoparticles (CuI@TiO $)$. New J. Chem. 2018, 42, 12062-12071. [CrossRef]

28. Karim-Nezhad, G.; Alipour, N. Electrocatalytic oxidation of hydrazine by copper iodide modified sol-gel derived carbon-ceramic composite Electrode. Curr. Chem. Lett. 2014, 3, 133-140. [CrossRef] 
29. Myeni, N.; Ghosh, S.K.; Perla, V.K.; Mallick, K. Copper iodide nanoparticles within the organic matrix: An efficient catalyst for the electro-oxidation of formic acid. Mater. Res. Express 2019, 6, 1050a7. [CrossRef]

30. Goodgame, D.M.L.; Goodgame, M.; Canham, G.W.R. Reversible Oxidation of Copper(I) Iodide in the Presence of Imidazole. Nature 1969, 222, 866. [CrossRef]

31. Gor'kov, K.V.; Talagaeva, N.V.; Hierso, J.C.; Bezverkhyy, I.S.; Pisareva, P.A.; Vorotyntsev, M.; Zolotukhina, E.V. Pd-PPy nanocomposite on the surface of carbon nanotubes: Synthesis and catalytic activity. Surf. Innov. 2017, 5, 121-129. [CrossRef]

32. Talagaeva, N.V.; Zolotukhina, E.V.; Bezverkhyy, I.; Konev, D.V.; Lacroute, Y.; Maksimova, E.Y.; Koryakin, S.L.; Vorotyntsev, M.A. Stability of Prussian Blue-polypyrrole (PB/PPy) composite films synthesized via one-step redox-reaction procedure. J. Solid State Electrochem. 2015, 19, 2701-2709. [CrossRef]

33. Talagaeva, N.V.; Zolotukhina, E.V.; Pisareva, P.A.; Vorotyntsev, M.A. Nanostructured Prussian Blue-polypyrrole composite coatings with electrochromic properties. Mendeleev Commun. 2016, 26, 119-120. [CrossRef]

34. Li, X.; Wan, M. Morphology and hydrophobicity of micro/nanoscaled cuprous iodide crystal. Cryst. Growth Des. 2006, 6, 2661-2666. [CrossRef]

35. Tavakoli, F.; Salavati-Niasari, M.; Mohandes, F. Green synthesis of flower-like CuI microstructures composed of trigonal nanostructures using pomegranate juice. Mater. Lett. 2013, 100, 133-136. [CrossRef]

36. Li, H.T.; Li, X.G. Preparation and characterization of cuprous iodide nanoparticles. Inorg. Mater. 2007, 43, 85-89. [CrossRef]

37. Silina, Y.E.; Morgan, B. LDI-MS scanner: Laser desorption ionization mass spectrometry-based biosensor standardization. Talanta 2021, 223, 121688. [CrossRef]

38. Semenova, D.; Silina, Y.E. The role of nanoanalytics in the development of organic-inorganic nanohybrids-Seeing nanomaterials as they are. Nanomaterials 2019,9, 1673. [CrossRef]

39. Almario, Á.A.A.; Vieira, R.L. Study of polypyrrole films modified with copper and silver microparticles by electrochemical cementation process. J. Chil. Chem. Soc. 2006, 51, 971-974. [CrossRef]

40. Madhu, R.N.; Awasthi, R. Polypyrrole Composites: Electrochemical Synthesis, Characterizations and Applications. Electropolymerization 2011. [CrossRef]

41. Salado, M.; Lanceros-Mendez, S.; Lizundia, E. Erratum to "Free-standing intrinsically conducting polymer membranes based on cellulose and poly(vinylidene fluoride) for energy storage applications". Eur. Polym. J. 2021, 144, 110240. [CrossRef]

42. Talagaeva, N.V.; Zolotukhina, E.V.; Pisareva, P.A.; Vorotyntsev, M.A. Electrochromic properties of Prussian blue-polypyrrole composite films in dependence on parameters of synthetic procedure. J. Solid State Electrochem. 2016, 20, 1235-1240. [CrossRef]

43. Talagaeva, N.V.; Kleinikova, S.A.; Gor'kov, K.V.; Zolotukhina, E.V. Electrochemical and electrocatalytic stability of Prussian blue/Berlin green redox transformation in Prussian blue-polypyrrole composite films. J. Solid State Electrochem. 2020, 24, 2935-2941. [CrossRef]

44. Mao, J.; Yang, L.; Yu, P.; Wei, X.; Mao, L. Electrocatalytic four-electron reduction of oxygen with copper (II)-based metal-organic frameworks. Electrochem. Commun. 2012, 19, 29-31. [CrossRef]

45. Wang, X.; Ke, Y.; Pan, H.; Ma, K.; Xiao, Q.; Yin, D.; Wu, G.; Swihart, M.T. Cu-Deficient Plasmonic Cu ${ }_{2-x}$ S Nanoplate Electrocatalysts for Oxygen Reduction. ACS Catal. 2015, 5, 2534-2540. [CrossRef]

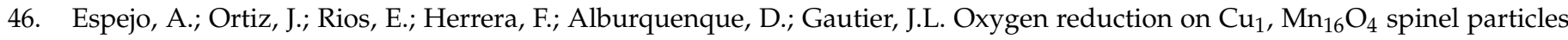
composite electrodes effect of particles size. J. Chil. Chem. Soc. 2014, 59. [CrossRef]

47. Jiao, C.; Jiang, X.; Chu, H.; Jiang, H.; Sun, L. A mixed-valent CuI/CuII metal-organic framework with selective chemical sensing properties. CrystEngComm 2016, 18, 8683-8687. [CrossRef]

48. Hassan, H.S.; Kashyout, A.B.; Morsi, I.; Nasser, A.A.A.; Abuklill, H. Development of polypyrrole coated copper nanowires for gas sensor application. Sens. Bio Sens. Res. 2015, 5, 50-54. [CrossRef]

49. Migneault, I.; Catherine, D.; Bertrand, M.J.; Waldron, K.C. Glutaraldehyde: Behavior in aqueous solution, reaction with proteins, and application to enzyme crosslinking. Biotechniques 2004, 37, 790-802. [CrossRef]

50. Bi, X.; Yang, K.L. Real-time liquid crystal-based glutaraldehyde sensor. Sens. Actuators B Chem. 2008, 134, 432-437. [CrossRef]

51. Miao, K.; Zhang, H.; Sun, L.; Zhu, Z.; Fan, L.J. Detection of glutaraldehyde in aqueous environments based on fluorescence quenching of a conjugated polymer with pendant protonated primary amino groups. J. Mater. Chem. C 2017, 5, 5010-5017. [CrossRef]

52. Wang, X.; Wu, P.; Lv, Y.; Hou, X. Ultrasensitive fluorescence detection of glutaraldehyde in water samples with bovine serum albumin-Au nanoclusters. Microchem. J. 2011, 99, 327-331. [CrossRef]

53. Karim-Nezhad, G.; Hasanzadeh, M.; Saghatforoush, L.; Ershadb, S.; Shadjoua, N. Kinetic study of the electro-catalytic oxidation of acetaldehyde on copper electrode. J. Chin. Chem. Soc. 2009, 56, 554-560. [CrossRef] 